\title{
Smart Farming for Lowland Strawberry (Fragaria $x$ ananassa) Production
}

\author{
Jayson J. Elenzano ${ }^{* 1}$, Jeve Warner A. Antonio ${ }^{* 2}$, Regino M. Cariaga ${ }^{* 3}$, Carmela Ann C. Dela Vega ${ }^{* 4}$, \\ Reygean Mary V. Gomez ${ }^{* 5}$, Jake C. Oranza ${ }^{* 6}$, Mark Lester B. Samaniego ${ }^{* 7}$ \\ 1,2,3,4,5,6,7 College of Engineering and Technology, Tarlac Agricultural University, Philippines \\ E-mail: *jjelenzano@tau.edu.ph
}

Article History: Received: 10 November 2020; Revised: 12 January 2021; Accepted: 27 January 2021;

Published online: 05 April 2021

\begin{abstract}
The developed system monitors the humidity levels, moisture content of the soil and surrounding temperature. Parameter values such as maximum and minimum temperature, maximum and minimum humidity values can be monitored accordingly by sending an sms to the system using arduino microcontroller, gsm module, moisture sensor and dht11 temperature/humidity sensor. This design maybe used for monitoring and controlling temperature and humidity value via sms. This system monitors and control the water content of the soil using a moisture sensor which runs under the control of a microcontroller, a dht 11 sensor to control and monitor the greenhouse humidity and proper temperature and a short messaging system (sms) to notify the caretaker/ owner on the moisture level content and temperature/humidity of the greenhouse. The system monitored and maintains the proper temperature, humidity and soil moisture content inside the greenhouse. The device has been successfully tested under simulated conditions and showed the ability of controlling temperature, humidity and soil moisture. The system notified the caretaker/farmer via short messaging system (sms) for the notification status (information) and triggering the water pump. The device showed the capability of sending sms holding the latest temperature and humidity information and also the status of the greenhouse.

Keywords: Smart farming, Arduino, humidity, temperature, automation
\end{abstract}

\section{Introduction}

However, in many emerging strawberry production areas, strawberry plant propagation, technologies are poorly developed and runner plants are often of low quality with relatively low carbohydrate content, root and crown infections with serious fungal plant pathogens and poor performance after transplanting.

Concern by lots of consumer for quality of agriculture products has stimulated awareness on the farmer to increase their crops in the market by implementing new technologies. The first thing that came to mind was how to control the use of natural resources and the environment which are the main factors in agriculture. The problem has taken the farmer's interest to implement agro-environmental remote monitoring in the agriculture industry. At the moment due to urbanization and lack of land availability, there is a great need to build greenhouses that can be utilized mostly for growing crops. With the growth and progress of technology, we can control and monitor multiple greenhouses easily with just a one click.

Monitoring and controlling of the greenhouses is one of the developments that the farmers can benefit. The farmers need not to visit the area to control and monitor the parameters inside the greenhouses. Also, this study is low-cost and the farmers do not need high capital investment since the materials to be used are locally available.

Benguet and Baguio are the common area s where strawberries are grown in the Philippines, one of which is in La Trinidad where strawberry picking is very popular. Growing of strawberries can be done in pots, hanging planters, special strawberry pots or in strawberry bed in the garden. One can grow his/her own strawberry to be economical since strawberry in stores are very expensive. Thus, this study is very beneficial hot areas or in lowland areas because one can control the environmental parameters needed by the strawberry plants.

The objective of this study was to developed a system that monitors the humidity levels, moisture content of the soil and surrounding temperature. Moreover, parameter values such as maximum and minimum temperature, maximum and minimum humidity values can be monitored accordingly by sending an SMS to the system. This system was developed by using Arduino microcontroller, GSM module, moisture sensor and DHT11 temperature/humidity sensor. Temperature and humidity inside the greenhouses can be monitored and controlled thru SMS.

\section{Methodology}




\subsection{Research Design}

The researchers used the Iterative and Incremental model to develop the system (Figure 1). The process basically involved (1) planning, (2) requirements, (3) analysis and design (4) coding, (5) implementation, (6) testing, and (7) deployment.

Planning. The researchers gathered the most useful and valuable information needed in regards to agriculture, growth of strawberry, and the management of greenhouses that will help the researchers formulate the step process that serves as their guidelines to meet all the requirements on their study.

Requirements. This phase was to gather and summarize all the different hardware and software requirements by the system such as Arduino microcontroller, Arduino IDE software, and Visual Basic.Net.

Analysis and Design. The researchers performed a detailed analysis and design about the system architecture and the set-up of the greenhouse of the study.

Coding. This phase was where the Arduino microcontroller was programmed using the Arduino IDE software and the Text File Sorting software was programmed and developed using Visual Basic.Net programming language.

Implementation. The researchers implemented the system in the greenhouse and based on the analysis and design that they developed.

Testing. This phase focused on conducting a complete test on how the system worked as a whole in a seventyday time frame.

Deployment. The researchers implemented the best plan that considers the system architecture and set-up of the greenhouse with the hardware specifications, different processes and modern technology that is needed to be in place for the study to be successfully installed that will be adopted by the system.

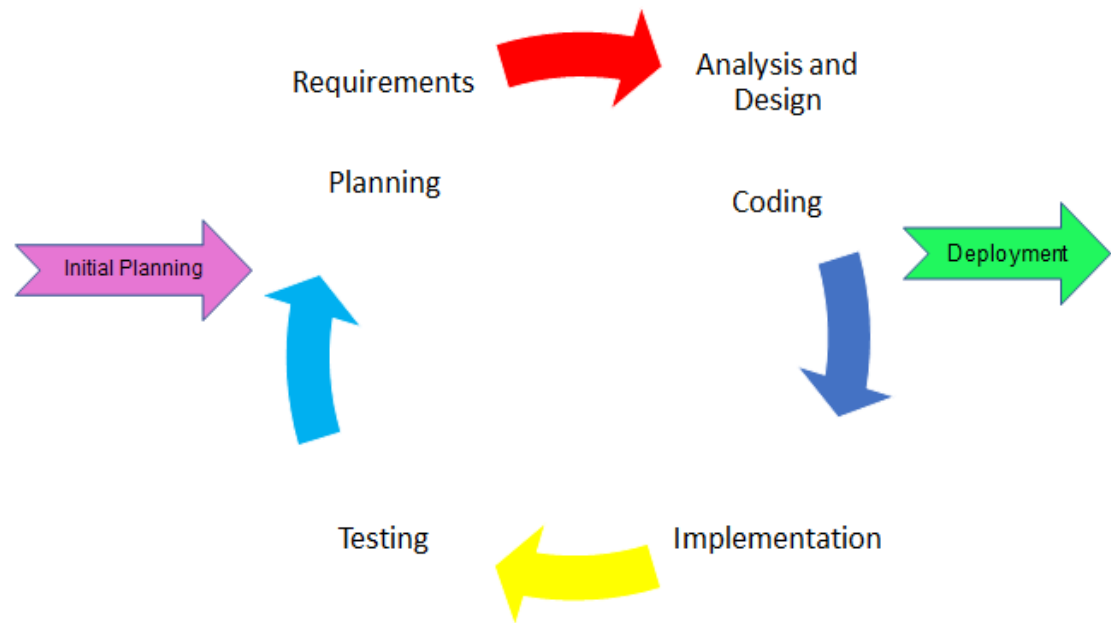

Figure 1. Development paradigm of the development of smart farming for Low land strawberry (Fragaria ananassa) production

\subsection{Data Gathering Procedure}

The study used different instruments in order to gather relevant data for the development of Smart Farming for the Lowland Strawberry Production. The instruments used are techniques which consist of research sampling and interview.

\section{Research Sampling}

The researchers used the manuscripts for the information about the agriculture and through greenhouse and the past studies which is related to their study to expand and increase their knowledge of the study. It is then that the researchers also used internet as a source to gather additional data as related to the proposed thesis topic. This 
helped the researchers to strive for a logical approach in searching for information on the specific topic or problem.

\section{Interview}

The researchers conducted a personal visit to the Central Luzon State University and performed an interview through Engr. Christopher Pascual to ask permission for the planting strawberry on how will survive in hot places. In order to support the validity of the data, interview has been conducted to gather information.

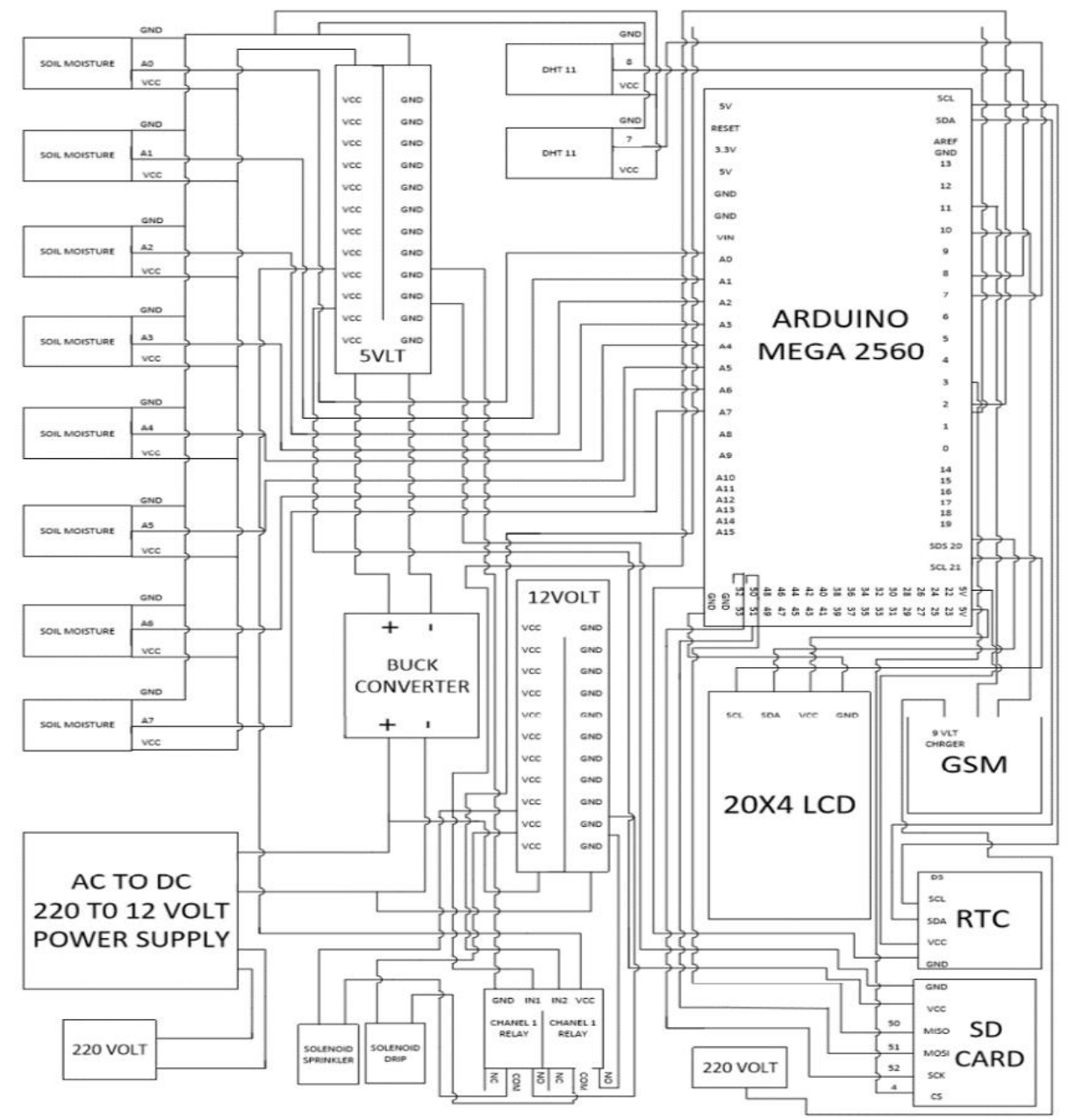

Figure 3. Full Circuit Design of Smart Farming for the Lowland Strawberry Production

Figure 3 shows the full circuit design of Smart Farming for the Lowland Strawberry Production. The Arduino Mega 2560 is the main board of the system that has a charger of $5 \mathrm{v}$ and it is connected to a $12 \mathrm{v}$ power supply. There are two (2) $12 \mathrm{v}$ solenoid valve. One is for soil moisture temperature and the other one was for the temperature sensor. The soil moisture sensor detects the moistness of the soil. This is the time that the soil moisture will send data to Arduino that triggering the one solenoid valve and the other one is triggered by DHT11 that detects temperature. The sensor will send the data to Arduino that will trigger either to open or close the solenoid valve and the Arduino will send the data to GSM and also be saved in the SD card.

The greenhouse measured $600 \mathrm{~cm}$ length $\times 296 \mathrm{~cm}$ width $\times 260 \mathrm{~cm}$ height. A solenoid valve that serves as the gateway of water, dripline hose that place water directly into the root zone and minimize evaporation, two (2) DHT-11 sensor that monitors the temperature and humidity inside the greenhouse, eight (8) soil moisture sensor that monitors the water content of the soil, five (5) sprinklers that dispersed water, Arduino Mega 2560 microcontroller that serves as the controller or the brain of the system.

The Smart Greenhouse contains two (2) plots with a size of $520 \mathrm{~cm}$ length $\mathrm{x} 75 \mathrm{~cm}$ width. Each plot has thirteen (13) strawberry plants with $50 \mathrm{~cm}$ between plants. A total of $70 \mathrm{~cm}$ distance between the plots and the zigzag method was used with $50 \mathrm{~cm}$ between the plants for more air circulation. The DHT-11 sensors 
(temperature and humidity sensors) were placed on each plot with a height of $1 \mathrm{~m}$. Each of the plots has four (4) soil moisture sensors with a distance of $100 \mathrm{~cm}$ each.

\section{Results and Discussion}

The Arduino system is the brain of the system. It serves as the control point of all trigger control line. The GSM module will send a notification for the soil moisture sensor that was used for determining the moisture content of the soil. Its purpose was to send a trigger signal to the microcontroller to trigger the solenoid valve for watering purposes. Also, the GSM module will send a notification for DHT-11 or temperature and humidity sensor was used for determining the heat level and air water content inside the greenhouse. In the system program, the researchers set a specific soil moisture content value and temperature and humidity value that change weekly.

The Smart Greenhouse was using an Arduino for programming the Arduino and upload the code from the computer. It is a ATMega2560 microcontroller board. It contains everything needed to support the microcontroller. It serves as the brain of the system. The researchers use it to sense and control both physically and digitally for the system of the greenhouse.

The following procedures had been used as a guide to the researcher in accomplishing these functionalities:

1. A non-corrosive moisture sensor was used in the greenhouse to monitor the moisture level of the strawberry. It composes of eight moisture sensor that were scattered throughout the greenhouse to have an equal monitoring and distribution of water in the greenhouse (Figure 2).

2 .

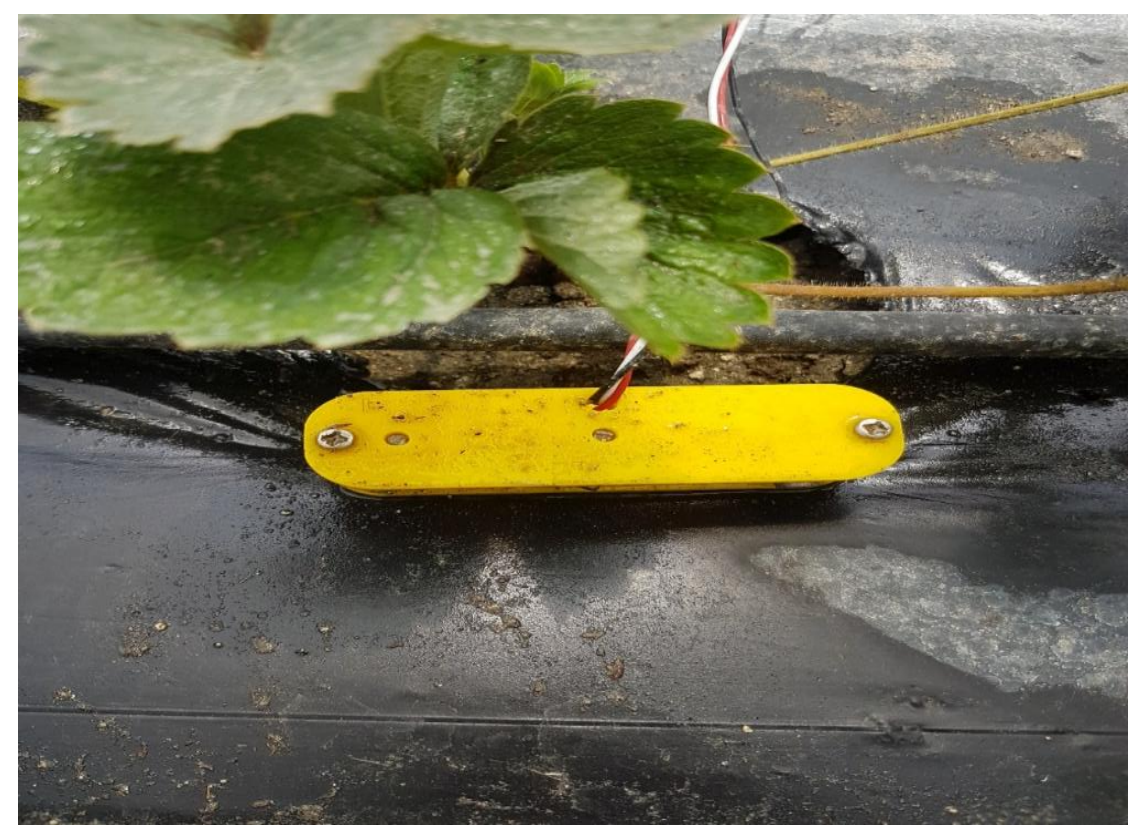

Figure 2. Soil Moisture Sensor

The Soil Moisture Sensor uses capacitance to measure the moisture of the soil. Simply insert this sensor into the soil to be tested, and therefore the volumetric water content of the soil is reported in percent. The researchers used the Soil Moisture Sensor to detect the moisture of soil if there was enough water around the sensor and it is compatible with the Arduino. Through an interview with experts in strawberry farming was done to meet the required water content of the strawberry. It was then calibrated based on the water requirement of the strawberry per day.

3. The DHT-11 sensor is composed of two parts, a capacitive humidity sensor and thermistor. There's also a very basic chip inside that does some analog to digital conversion and spits out a digital signal with the temperature and humidity. The researchers used the DHT-11 to monitor the air temperature and air water content inside the greenhouse. Also, the researchers used the data from the sensor as basis to trigger the sprinklers. Each plot of the greenhouse has one DHT-11 sensor (Figure 3). 


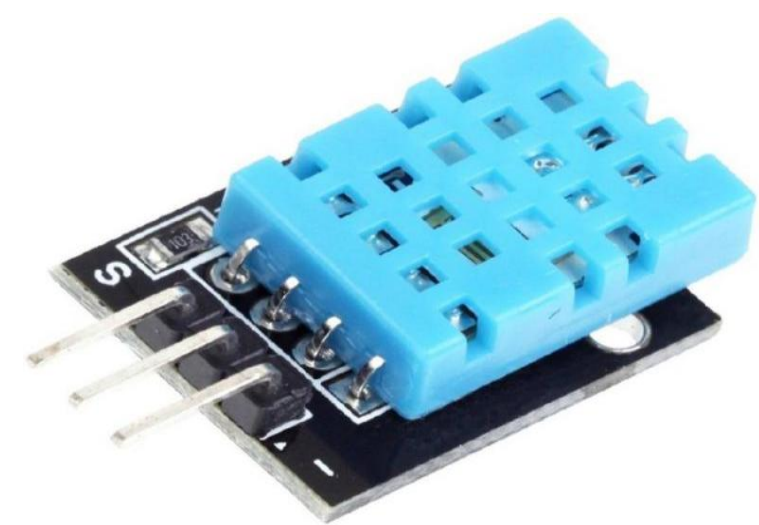

Figure 3. Three Pin DHT-11 Sensor (Humidity and Temperature)

4. A drip-line were installed that was connected to the solenoid valve to regulate the turning on and off with respect to the moisture sensor. The drip irrigation system is the most effective method of irrigating. It has the potential to save water and nutrients by letting water to drip slowly to the roots of plants. The researchers used this to place the water directly into the root zone and minimize evaporation (Figure 4).

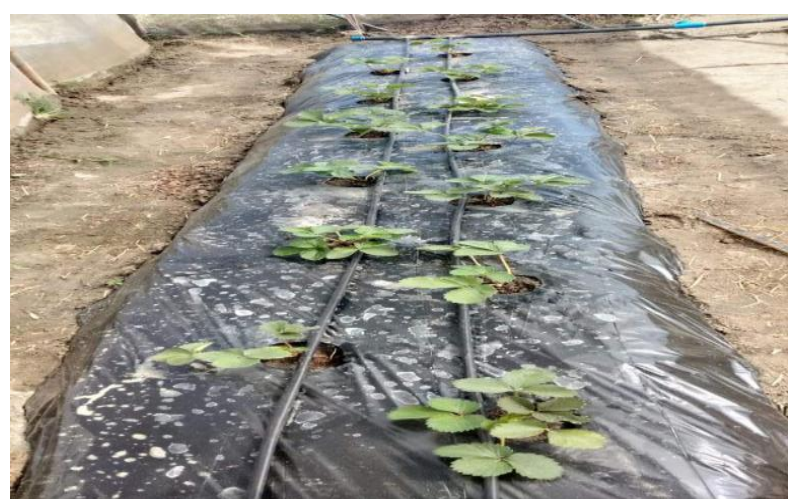

Figure 4. Drip Irrigation System

5. To notify the caretaker/ greenhouse owner/ farmer via Short Messaging System (SMS) on the moisture level content and temperature/humidity of the greenhouse (Figure 5).

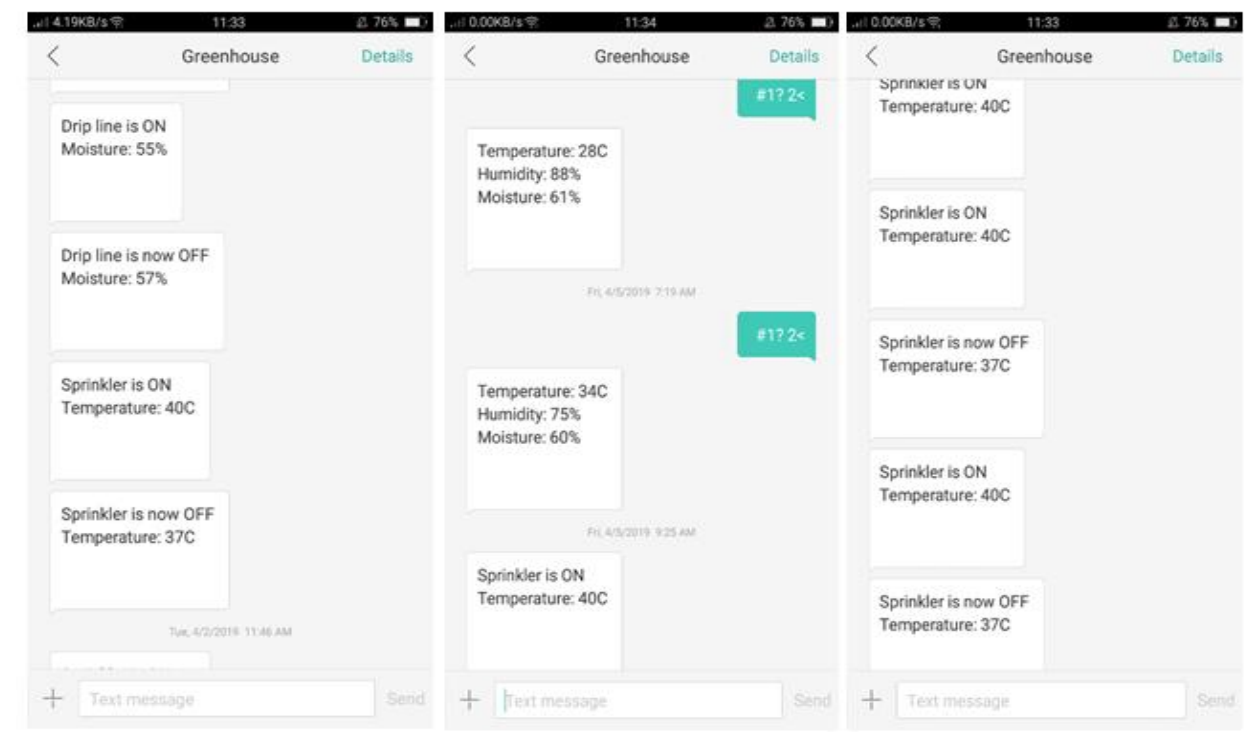

Figure 5. Text Smart Greenhouse of GSM

The Smart Greenhouse notifies the caretaker for the status of the Greenhouse. This When the temperature reaches $40^{\circ} \mathrm{C}$ the sprinkler will trigger it $\mathrm{ON}$ to sprinkler the greenhouse and when it reaches to $37^{\circ} \mathrm{C}$, the 
sprinkler will be automatically OFF. Also, when the moisture reaches 55\% the dripline irrigation will trigger it ON to sprinkler the plant and when it reaches to $57 \%$, the dripline irrigation will be automatically OFF.

The study of Amaya Diaz Juan Carlos et al (2020) and Hussain et al. (2020) used the Internet of Things (IOT) Platform and a mobile phone in the strawberry crops to monitor the relative humidity, temperature of the greenhouse system.

6. Growth rate of the strawberries (smart greenhouse vs ordinary green house);

Based on the comparison of the ordinary greenhouse and smart greenhouse using T-Test, there is no significant relationship between the growth rate of strawberries in both greenhouses.

On week 8 , fruits starting to come out from the pollinated flower buds on both greenhouses. The researchers counted of each crop in each plot the fruit bearings of the strawberry for both methods. All of the counted date of the crops was added per plot to get the average fruit-bearing of the plants. The final average fruit bearings of Smart Greenhouse was $80 \mathrm{~g}$ while the final average fruit bearings of Ordinary Greenhouse was $20 \mathrm{~g}$.

On week 6, flower buds on ordinary and smart greenhouse coming out as a sign of maturity period of strawberries and ready for fruiting stage. The final average number of flowers in Smart Greenhouse was 62 while the final average number of flowers in Ordinary Greenhouse was 38.

The researcher recorded the data for water consumption for the two methods. The researchers measured and calculated the total volume of water dispensed per day. In Ordinary Greenhouse, a total of (7) seven liters of water per plant per day was dispersed for the two plots, while in Smart Greenhouse, the researchers measured and calculated the total volume of water dispersed based on the data gathered using the data logging module. $20 \mathrm{ml}$ per minute on dripline and $210 \mathrm{ml}$ per minute for the mist fogger. It shows that the Ordinary Greenhouse consumes more water than the Smart Greenhouse.

The Smart Greenhouse notifies the caretaker for the status of the Greenhouse. This When the temperature reaches $40^{\circ} \mathrm{C}$ the sprinkler will trigger it $\mathrm{ON}$ to sprinkler the greenhouse and when it reaches to $37^{\circ} \mathrm{C}$, the sprinkler will be automatically OFF. Also, when the moisture reaches $55 \%$ the dripline irrigation will trigger it ON to sprinkler the plant and when it reaches to $57 \%$, the dripline irrigation will be automatically OFF.

The study of Kadir, Sorkel \& Sidhu, Gaganpreet \& Al-Khatib, Kassim. (2006) shows that the overexposure to $40 \mathrm{o} C$ temperature of the strawberry will lead to detrimental of the flowers and fruits of the strawberries. Also, the effects of heat stress to the strawberries need also to be considered in the study of heat tolerance during the reproduction of runners.

To compare the lowland strawberries and Baguio strawberries, an evaluation is done on tasting the strawberry was obtained by surveying students and faculties at Tarlac Agricultural University in Camiling, Tarlac. The choices on rating the strawberry are like very much, like moderately, like a little, neither like or dislike, dislike a little, dislike moderately, and dislike very much. Strawberry A represents the strawberry from the Ordinary Greenhouse, strawberry B represents the strawberry from the Smart Greenhouse, and the strawberry C represents the strawberry from Baguio. A total of 13 respondents actually tasted the strawberries. The respondents are composed of students, faculty and non-teaching personnel of the University.

The Baguio Strawberry has a mean of 5.92. This result based on the smell test conducted show that the smell of Baguio strawberries are more fragrant than the lowland strawberries but not that far away. The Smart Greenhouse Strawberry has a mean of 5.85. It shows based on the smell test conducted that the smell of Smart Greenhouse Strawberry are more fragrant than the Ordinary Greenhouse Strawberries. The Ordinary Greenhouse Strawberry has a mean of 5.62. It shows that the smell of the Strawberry in the Ordinary Greenhouse are less fragrant than the strawberry of Baguio and Smart Greenhouse.

Based on the evaluation, the smart greenhouse strawberries got the highest score with the mean on 6.15 with a verbal description of highly acceptable. The Ordinary Greenhouse and Baguio Strawberryshare the same score with the mean of 5.38, as well as verbal description of acceptance. Harvest and proper packaging of strawberries has a great effect on the physical appearance. Because strawberries have a very delicate texture, due to packaging and travel time the strawberries got bumps and bruises that causes the physical appearance to look not so appealing. 
The taste of smart greenhouse has a mean of 5.69 (like moderately) and acceptable to the respondents. While the Baguio strawberries has a mean of 5.46 and with its mild sour taste, the ordinary greenhouse got a 4.92 mean and thus moderately acceptable to the respondents.

The sweetness taste of the smart greenhouse got a mean of 5.31 and they like moderately. While the Baguio strawberries got 5.08 mean which is moderately acceptable and the ordinary greenhouse has 4.54 mean (moderately acceptable).

\section{Conclusion}

The system was successfully implemented in the greenhouse. The system is working properly that is to get temperature, humidity and soil moisture. The communication is properly done between temperature, humidity and soil moisture, and Arduino Mega 2560.

The system monitored and maintain the proper temperature, humidity and soil moisture content inside the greenhouse. The device has been successfully tested under simulated conditions and showed the ability of controlling temperature, humidity and soil moisture.

The System notified the caretaker/farmer via Short Messaging System (SMS) for the notification status (information) and triggering the water pump. The device showed the capability of sending SMS holding the latest temperature and humidity information and also the status of the greenhouse.

\section{References}

1. Abdul et al, (2009). Remote Monitoring in Agricultural Greenhouse Using Wireless Sensor and Short Message Service (SMS). International Journal of Engineering and Technology.

2. Amaya Diaz Juan Carlos et al, (2020). Monitoring System of Environmental Variables for a Strawberry Crop Using IOT Tools. Procedia Computer Science 170 (2020) 1083-1089, https://doi.org/10.1016/j.procs.2020.03.067.

3. Agustin et al, (2018). Automatic Sprinkler and Supplemental Heat Lights Using Android-Based Environmental Sensor for Greenhouse. Tarlac Agricultural University, Malacampa, Camiling, Tarlac.

4. Berezowski, (2012). The Landscape of Wireless Sensing in Greenhouse Monitoring and Control. Wroclaw University of Science and Technology.

5. Chiung et al, (2011). Greenhouse Environment System Based on Remote Control. International Conference on Chemical, Ecology and Environmental Sciences.

6. Deore and Umale, (2012). Wireless Monitoring of the Greenhouse System Using Embedded Controllers. International Journal of Scientific and Engineering Research.

7. E. Avşar, K. Buluş, M. A. Saridaş and B. Kapur, (2018). Development of a cloud-based automatic irrigation system: A case study on strawberry cultivation. 2018 7th International Conference on Modern Circuits and Systems Technologies (MOCAST), Thessaloniki, 2018, pp. 1-4, doi: 10.1109/MOCAST.2018.8376641

8. Elmusrati et al, (2008). Greenhouse Monitoring with Wireless Sensor Network.

9. Farm Monitoring Systems for Agriculture, (2015). Smart Strawberries Crop Increases the Quality and Reduce the Time from Farm to Market. Smart agriculture Waspmote.

10. Hussain, A., Manikanthan, S.V., Padmapriya, T., Nagalingam, M. (2020). Genetic algorithm based adaptive offloading for improving IoT device communication efficiency. Wireless Networks, 26 (4), pp. 2329-2338.

11. Jeong, Y. K., 정영균, Lee, J. G., Ahn, E. K., Seo, J. S., Kim, H. T., ... 윤용철. (2019). Analyzing the Performance of a Temperature and Humidity Measuring System of a Smart Greenhouse for Strawberry Cultivation. Protected Horticulture and Plant Factory, 28(2), 117-125. https://doi.org/10.12791/ksbec.2019.28.2.117.

12. Kadir, Sorkel \& Sidhu, Gaganpreet \& Al-Khatib, Kassim. (2006). Strawberry (Fragaria Xananassa Duch.) Growth and Productivity as Affected by Temperature. HortScience. 41. 1423-1430. 10.21273/HORTSCI.41.6.1423.

13. Ayaz, et al, (2019). Internet-of-Things (IoT)-Based Smart Agriculture: Toward Making the Fields Talk. IEEE Access PP(99):1-1

14. Mustafa Alper Akkaş et al, (2017). An IoT-based greenhouse monitoring system with Micaz motes. International Workshop on IoT, M2M and Healthcare (IMH 2017).

15. Nachidi et al, (2006). Temperature and Humidity Control in Greenhouses Using the Takagi-Sugeno Fuzzy Model. International Conference on Control Applications. 
16. Nikhade and Nalbalwar, (2013). Monitoring Greenhouse Using Wireless Sensor Network. International Journal of Advance Computer Research.

17. Othman and Shazali, (2012). Wireless Sensor Network Applications: A Study in Environment Monitoring System. International Symposium on Robotics and Intelligence Sensor.

18. Palaniappan et al, (2009). Monitoring of an Aeroponic Greenhouse with a Sensor Network. International Journal in Computer Science and Network Security.

19. Qian et al, (2014). A Wireless Solution for Greenhouse Monitoring and Controlling System Based on ZigBee Technology. Journal of Zheijiang University Science.

20. Rahali et al, (2011). Development of a Data Acquisition and Greenhouse Control System Based on GSM. Journal of Engineering, Science and Technology.

21. Stipanicev and Marasovic, (2003). Network Embedded Greenhouse Monitoring and Control. International Journal in Scientific Research Publications.

22. Zagade and Kawitkar, (2012). Wireless Sensor Network for Greenhouse. International Journal of Science and Technology. 